\title{
An Evaluation on Urban Green Space System Planning Based on Thermal Environmental Impact
}

\author{
Yue Liu1,2, Jiao Li ${ }^{3}, \mathrm{Su} \mathrm{Li}^{4}$ \\ ${ }^{1}$ Architectural and Urban Planning Design \& Research Institute of Huazhong University of Science and Technology, Wuhan, China \\ ${ }^{2}$ School of Architecture and Art, Central South University, Changsha, China \\ ${ }^{3}$ Zhuzhou Planning and Design Institute, Zhuzhou, China \\ ${ }^{4}$ School of Art and Architecture, Central South University, Changsha, China \\ Email: ${ }^{*} 75119640 @ q q . c o m$
}

How to cite this paper: Liu, Y., Li, J., \& Li, S. (2017). An Evaluation on Urban Green Space System Planning Based on Thermal Environmental Impact. Current Urban Studies, 5, 68-81.

https://doi.org/10.4236/cus.2017.51005

Received: February 16, 2017

Accepted: March 26, 2017

Published: March 29, 2017

Copyright $\odot 2017$ by authors and Scientific Research Publishing Inc. This work is licensed under the Creative Commons Attribution International License (CC BY 4.0).

http://creativecommons.org/licenses/by/4.0/ (c) †) Open Access

\begin{abstract}
From the ecological effect of urban green space system, this paper illustrates the necessity and importance of inter-disciplinary evaluation of the urban green space system from the ecological perspective and analyzes the mechanism of action of urban green space in relieving the heat island effect. The quantitative evaluation approach for the thermal environmental impact of urban green space system is proposed utilizing GIS technology. Zhuzhou is taken as an example for practical application of the approach. Lastly, priority issues in relation to urban green space system planning and quantitative evaluation are discussed.
\end{abstract}

\section{Keywords}

Urban Green Space System, Heat Island Effect, GIS, Thermal Environment, Ecological Evaluation

\section{Introduction}

Due to their significance to cities, people pay great attention to urban green spaces. In practice, urban green space planning often features rigid management since it's difficult to make revisions after the plans are worked out. Urban green space land is land for public use, so there are economic coordination issues, making rational planning of urban green space vitally important (Wang, 2009). Finding a way to make urban green space system planning more scientific and rational has become an urgent issue to be addressed.

Urban green spaces are known to a wide range of positive external functions 
in relation to spatial organization, landscaping, economy, temperature reduction, dust reduction and disaster prevention. Among them, the evident mitigation of the heat island effect is considered the major ecological function of urban green spaces ${ }^{1}$. The past two decades have seen fruitful studies on the relationship between urban green spaces and the thermal environment, and a number of studies have verified the measurable impact of urban green spaces on the surrounding thermal environment. Scholars A.H. Rosenfeld et al. (1998), Wu et al. (2007), Gao et al. (2009) and Lei et al. (2011) have analyzed the quantitative effects of green spaces on the thermal environment respectively from the perspectives of the area, vegetation and form of the green spaces.

As suggested in the abovementioned research, the ecological role of green spaces should be taken into full consideration in the evaluation of urban green space system planning, and ecological evaluation of green space systems should be taken as one of the major factors used to determine the rationality of urban green space system planning. The current evaluation methods for urban green space system planning reveal an emphasis on urban green space area, accessibility, and economic effect; there are a few studies related to ecology, yet they are confined to macro aspects such as conceptual introduction and theoretical application; research methods are mostly qualitative (Fu, Song, \& Ding, 2006; Hu, 2007; Zhu, 2011; Gao, 2015) and can't help determine the ecological impact of urban green space systems.

As a matter of fact, the quantitative research on the ecological effects of green spaces is well-established, and has laid a good foundation for ecological evaluation of urban green space system planning. The causes of the inadequacy in ecological evaluation of urban green space systems primarily lie in industrial and disciplinary differences: on the one hand, the research on the ecological effects of green spaces is concentrated on agriculture and forestry, weather and environmental protection. Urban green spaces construction is mostly decided on by urban construction and planning departments, thus industrial differences have resulted in a limited grasp of the mechanisms of ecological effects and inadequate application in the planning and construction of urban green spaces. On the other hand, relevant research is focused on the patterns of action of ecological impact for individual green spaces. Since green spaces constitute a system, studies on the association between the ecological impact of green spaces and city features should be conducted. The interdisciplinary nature has made relevant research and practices lag behind.

This research is based on the perspective of integrating disciplines, and proceeds from the major ecological functions of urban green spaces, incorporating the patterns of ecological effect of green spaces into the evaluation of urban green space system planning. With an emphasis on the combination of

${ }^{1}$ Global warming is always an issue receiving attention. According to mainstream viewpoints, warming will result in such consequences as extreme weather and disasters, sea level rise, ecological imbalance and disease transmission, and thus constitute a severe threat to the survival of mankind. As man's main production and living places, cities are closely related to warming. The heat island effect of cities is considered the major ecological issue in urbanization. 
quantitative effects of green spaces and urban land, population and other features, GIS technology has been adopted to conduct ecological evaluations on the rationality of urban green space system planning. Hence, this research will be of great significance to the improvement of urban green space system evaluation mechanisms and providing guidance on urban green space system planning and development.

\section{Temperature Reduction Mechanism of Urban Green Spaces}

\subsection{Direct Temperature Reduction Effect}

1) Heat dissipation through plant transpiration. Research indicates that the water absorption, transpiration and heat dissipation performed by plants are the major factors in temperature reduction around the plants (Kang et al., 2005). Through transpiration, the leaves of green plants can emit a large amount of thermal energy (Hao, 2004).

2) Solar radiation reduction by photosynthesis. By absorbing solar energy, plants are in a constant process of photosynthesis with the raw materials of water and carbon dioxide. One aspect of this is that $60 \%$ to $80 \%$ of the solar radiation can be absorbed by green plants, reducing the heat source for increase of air temperature and greatly weakening the radiation of heat from the Earth's surface due to solar radiation. Another aspect is that a large amount of the major greenhouse gas carbon dioxide can be absorbed through photosynthesis, greatly decreasing the carbon dioxide concentration in the atmosphere, and thus realizing the mitigation of greenhouse effect and reduction of ambient temperature.

\subsection{Indirect Temperature Reduction Effect}

1) Solar radiation shielding by tree leaves. Tree leaves can reflect and keep out solar radiation. With a better sun-shading effect than certain artificial structures, they can reduce the absorption and storage of heat radiation of the shaded structures and surfaces, and thus result in a slower temperature increase on the surfaces and structures.

2) Local breeze formation in the city by plant communities. Temperature and atmospheric pressure differences form between the hot and cold air of the architectural complex area and green space area of the city, and subsequently a huge air flow is generated between the two areas. Air circulation can reduce the temperature of urban architectural complexes and realize temperature reduction (Wang, 2007).

\subsection{Quantitative Relationship of Temperature Reduction of Urban Green Spaces}

The quantitative relationship of temperature reduction on the surrounding thermal environment by urban green spaces can be acquired by TM remotesensing image or field measurement (Sun et al., 2016). The law of this effect is reflected in the following two aspects: 
1) As shown by the research, the temperature in the areas surrounding green spaces gradually rises starting from the boundary of the green spaces. The temperature difference between the surrounding temperature and boundary temperature $(\Delta \mathrm{T})$ increases with the distance from the boundary of the green spaces with a declining trend. When the distance reaches the maximal effect value, the temperature difference $(\Delta \mathrm{T})$ will also arrive at the maximal value and the impact of green spaces on the surrounding temperature will come to an end. Their relationship is similar to a cubic polynomial through the origin (Figure 1) (Su et al., 2010).

2) The above feature results in the maximal impact distance of green spaces on surrounding temperature reduction. As revealed in the study, the temperature reduction impact distance of green spaces is positively correlated with the area of the green spaces. The larger the area, the greater the temperature reduction impact, and vice versa. When the green space area is given, the temperature reduction impact distance can be acquired by linear relation $(\mathrm{Wu}, 2010)$.

\section{Evaluation Methods of Thermal Environmental Impact for Urban Green Space System Planning}

\subsection{Thermal Environment Impact Factors of Urban Green Space Systems}

\section{1) Features of Green Spaces}

The area, botanical constitution and growth conditions of green spaces have a direct impact on the thermal environment of the green spaces. Since their area is relatively constant and the botanical constitution and growth conditions can be adjusted, the differences in their dynamic features should be removed in the evaluation of thermal environment impact of green space systems, so as to provide a more objective judgment on the rationality of green space system layout. Only the area of green spaces is taken into consideration in this study.

2) Population Distribution and Land Usage

Population distribution determines the effect of green space systems on the thermal environmental impact. The urban green space system should be established in densely populated and actively used areas as much as is practically

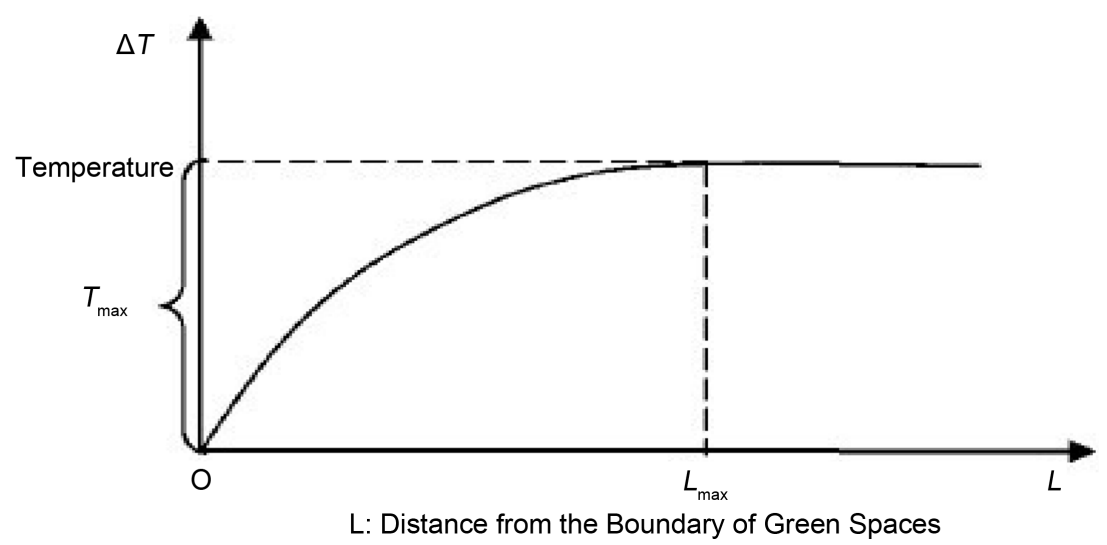

Figure 1. Fitted curve model diagram of $\Delta \mathrm{T}$ and $\mathrm{L}$. 
possible. Sparsely populated areas do not need to be considered. In green space system layout, therefore, residential land should be considered first, commercial service industry land and public management and public service facilities second, and industrial land last. The minimum requirements are for other land for storage or municipal facilities.

\subsection{Technical Route of Evaluation}

In this study, the working framework for thermal environment evaluation of urban green space systems is established with GIS technology. Firstly, a data platform is established with GIS. Secondly, the total range of temperature reduction and ranges of temperature differences are computed based on the law of green space temperature reduction effect. Lastly, overlay analysis is conducted with planned land and population conditions to obtain the evaluation results (Figure 2).

\subsection{Evaluation Modeling}

An evaluation model is established with GIS technology as follows:

1) A database is established for regional green space, planned land utilization and population distribution research

The green space spatial data in the research area is extracted and the area computed; the land utilization plan of the research area is obtained, and such information as planned land usage, area and degree of development per plot is collected; the planned population on each plot is allocated based on plot information and the overall population planning to generate the population distribution data.

2) The temperature impact range is calculated and generated

The linear relation of the impact range of green space area on the surrounding temperature field can be determined by local temperature data from the city. The maximal impact range $\mathrm{D}$ can be calculated from the green space area. The buffer area can be generated from the buffer distance of the maximum impact range $\mathrm{D}$ of the green spaces.

3) Temperature difference range is calculated

After determining the fitted cubic polynomial of the research area, the $\mathrm{D}$ value of the green spaces can be substituted into the formula to acquire the maximal

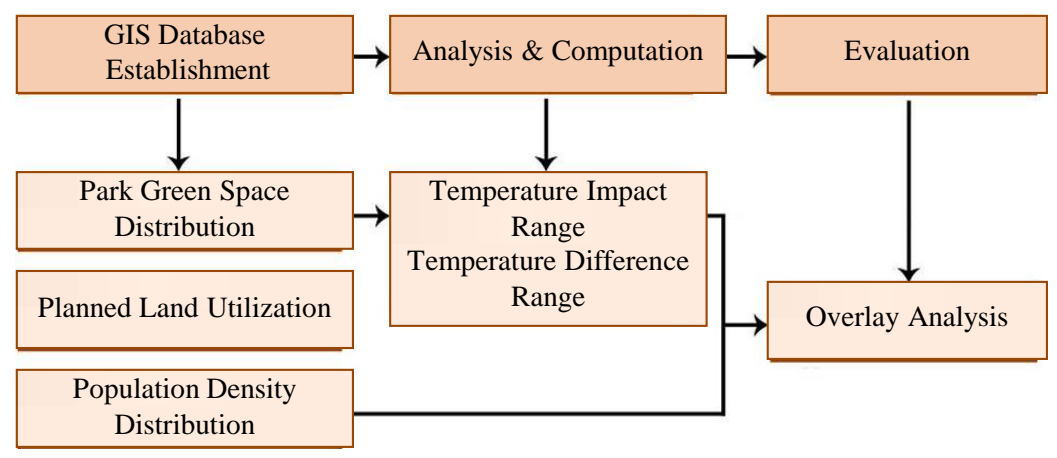

Figure 2. The technical route of evaluation. 
green space temperature difference ( $\Delta$ Tmax). When the temperature difference zone is set in each $\Delta T \max$, the impact range of the temperature difference zone of a green space can be calculated to generate the buffer area.

\subsection{Evaluation Indexes and Methods}

GIS evaluation model data is used to perform overlay calculations on the total range of temperature reduction of green spaces, the temperature difference zone range and urban land usage, and population data. The following three indexes can then be adopted to assess the thermal environment impact effect of urban green space planning, i.e., ecological service conditions:

1) Index I: Service area and population ratio

The ratio of green space ecological service area and service population to the total area and total population of the research area is an important index to measure the total ecological service level of green spaces. This overall index can be used to compare the green space ecological efficiency of different areas or different cities. They can be expressed in the following formulas:

Service area ratio $=$ service area/total area of research area $\times 100 \%$

Service population ratio $=$ service population/total population of research area $\times 100 \%$

2) Index II: Residential area and residential population service ratio

Requirements on residential land are much higher than those for commercial, industrial and public service land. Therefore, the residential area and population ratio that green spaces service constitute a significant aspect to measure the rationality of green space system layout. They can be expressed in the following formulas:

Residential area service ratio $=$ Residential area serviced/total service area $\times 100 \%$

Residential population service ratio $=$ Residential population serviced $/$ total service population $\times 100 \%$

3) Index III: Statistics of temperature difference service level

The area and population ratio within the temperature difference service range are an index for further reflecting the green space service level. Relatively speaking, the greater the service area and service population within small temperature difference areas, the higher the service level. They can be expressed in the following formulas:

Service area ratio within a certain temperature difference $=$ Service area within a certain temperature difference/total service area $\times 100 \%$

Service population ratio within a certain temperature difference $=$ Service population within a certain temperature difference/total service population $\times 100 \%$

\section{Green Space Thermal Environment Impact Evaluation Case Study}

\subsection{Research Area Selection}

Tianyuan District, Zhuzhou City was selected as the research area. Relatively complete and independent, the area experiences little temperature reduction 
from the park green spaces in other districts (In the north and east of the District, the river is bounded, and the West and the south are the rural land) (Figure 3). The green space system planning in the research area includes $8 \mathrm{mu}$ nicipal parks and 9 district-level parks. The name, area and types of these parks are listed in Table 1.

\subsection{Data Preparation}

On the basis of Zhuzhou Specialized Planning for Green Space System (2010-2020), Tianyuan District Land Use Planning, Tianyi Demonstration Zone Overall Planning (2010-2030) and other basic data, the space and attribute data in relation to the nature, area, degree of development and population density of the park green spaces and other land is established in GIS, and the population density distribution diagram is thus generated (Figure 4);

The park green spaces are taken as buffer elements, and the surrounding temperature field impact range (D) is taken as the buffer distance for the external buffer and merged to generate the maximal impact range diagram for the park green spaces.

The park green spaces are taken as buffer elements, and the green space impact range $(\mathrm{L})$ on temperature differences in the surrounding temperature fields $(\Delta \mathrm{T}=1.0, \Delta \mathrm{T}=1.5, \Delta \mathrm{T}=2, \Delta \mathrm{T}=2.5, \Delta \mathrm{T}=3, \Delta \mathrm{T}=3.5, \Delta \mathrm{T}=4.0)$ as the buffer

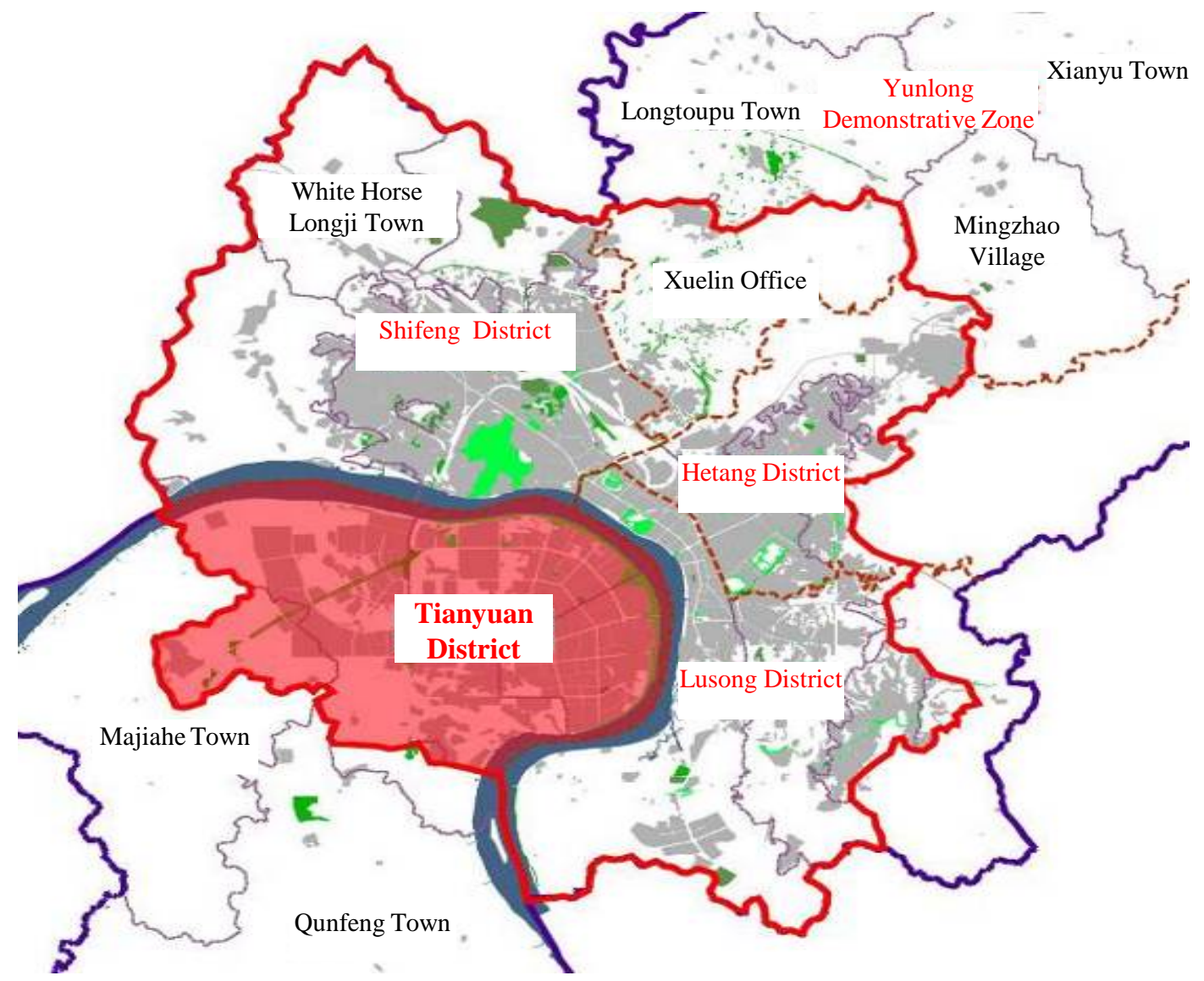

Figure 3. Tianyuan district location map. 
Table 1. List of municipal and district level planned parks in Tianyuan district in Zhuzhou city.

\begin{tabular}{|c|c|c|c|c|}
\hline Level & Name of Park & Area (Hectares) & Type & Remarks \\
\hline \multirow{8}{*}{ Municipal } & Shennong City & 125.51 & Multi-functional Park & Existing \\
\hline & Xiang River Landscape Belt (Hexi Section) & 337.91 & Multi-functional Park & Existing \\
\hline & Wanfenggang Wetland Park & 71.11 & Eco Park & Under Planning \\
\hline & Xiangjiang New City Forest Park (I) & 134.04 & Eco Park & Under Planning \\
\hline & Xiangjiang New City Forest Park (II) & 182.91 & Eco Park & Under Planning \\
\hline & Xiangjiang New City Forest Park (III) & 46.51 & Eco Park & Under Planning \\
\hline & Cangshagang Wetland Park & 107.76 & Eco Park & Under Planning \\
\hline & Nantang Reservoir Wetland Park & 88.21 & Eco Park & Under Planning \\
\hline \multirow{9}{*}{ District-level } & Liyu Park & 34.78 & Multi-functional Park & Existing \\
\hline & Xintang Park & 32.33 & Multi-functional Park & Under Planning \\
\hline & Central Park & 52.64 & Multi-functional Park & Under Planning \\
\hline & Olympic Park & 9.88 & Specialized Park & Existing \\
\hline & Wuguang Sports Park & 69.62 & Specialized Park & Under Planning \\
\hline & Sculpture Park & 45.98 & Specialized Park & Under Planning \\
\hline & Art Forest & 117.85 & Specialized Park & Under Planning \\
\hline & Xiangshuiwan Park & 115.46 & Tourism \& Recreational Green Space & Under Planning \\
\hline & Car Theme Park & 220.81 & Specialized Park & Under Planning \\
\hline
\end{tabular}

Data Source: Zhuzhou Specialized Planning for Green Space System (2010-2020).

distance for the external buffer to generate the impact range isothermals of temperature differences ${ }^{2}$;

With GIS, overlay calculations are performed on the maximal impact range of park green spaces, impact range of temperature differences, land use and population data to generate the final base data for evaluation and analysis (Figure $5 \&$ Figure 6).

\subsection{Analysis Results and Evaluation}

\section{1) Overall Impact Analysis}

As can be seen from the overall planning of Tianyuan District, the temperature reduction impact range of park green spaces doesn't cover all urban areas. There is a good coverage in the eastern and southern areas, and a poor coverage in the central areas with a small portion of urban land. The affected overall area accounts for $45.33 \%$ of the total urban area in Tianyuan District, and the affected population accounts for $46.61 \%$ of the total population in Tianyuan District. It can be seen that over $50 \%$ of the urban land and urban population are unable to enjoy the temperature reduction impact brought by park green spaces.

\section{2) Analysis on Service Level of Residential Land}

${ }^{2}$ As verified by trial computation and data, the computational formulas of green space impact range and surrounding temperature difference range in this study respectively are: $\mathrm{D}=0.0004 \mathrm{~S}+139.2$ (D: temperature reduction impact distance of each green space; $\mathrm{S}$ : green space area). $\Delta \mathrm{T}=$ $0.00000002 \mathrm{~L} 3-0.00003083 \mathrm{~L} 2+0.01699873 \mathrm{~L}(0<\mathrm{L}<\mathrm{D})$ (L: distance from the boundary of green space). 


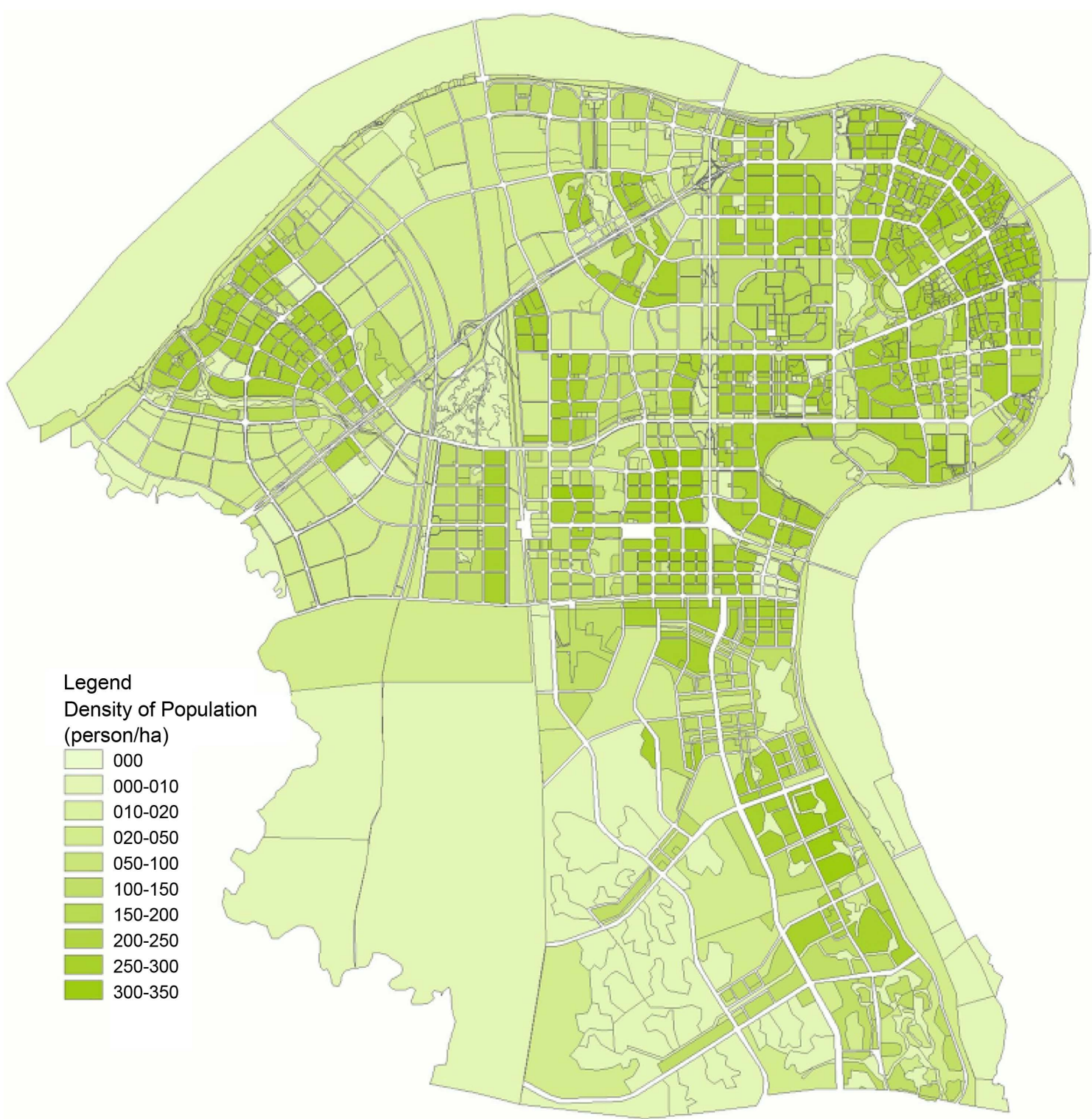

Figure 4. Distribution map of population density in Tianyuan district.

The affected area and population for different urban land uses can be calculated (Figure 7). It can be seen that the affected area and population in residential areas respectively take up $49.53 \%$ and $70.92 \%$ of the total service area and population. It indicates that the park green spaces are concentrated in densely populated areas and the residential population benefits most from the park green spaces. Therefore, the layout is relatively rational.

3) Analysis on Service Level of Temperature Differences

As shown in Figure 8, temperature differences at $\Delta \mathrm{T}=2.5^{\circ} \mathrm{C}$ and $\Delta \mathrm{T}=3.0^{\circ} \mathrm{C}$ exert the greatest impact and account for about $50 \%$ of the total service area and population. The impact area of small temperature differences is relatively small. Therefore, small community parks should be increased and more residential land should be planned around the parks in planning.

4) Analysis of Service Level of Different Areas 


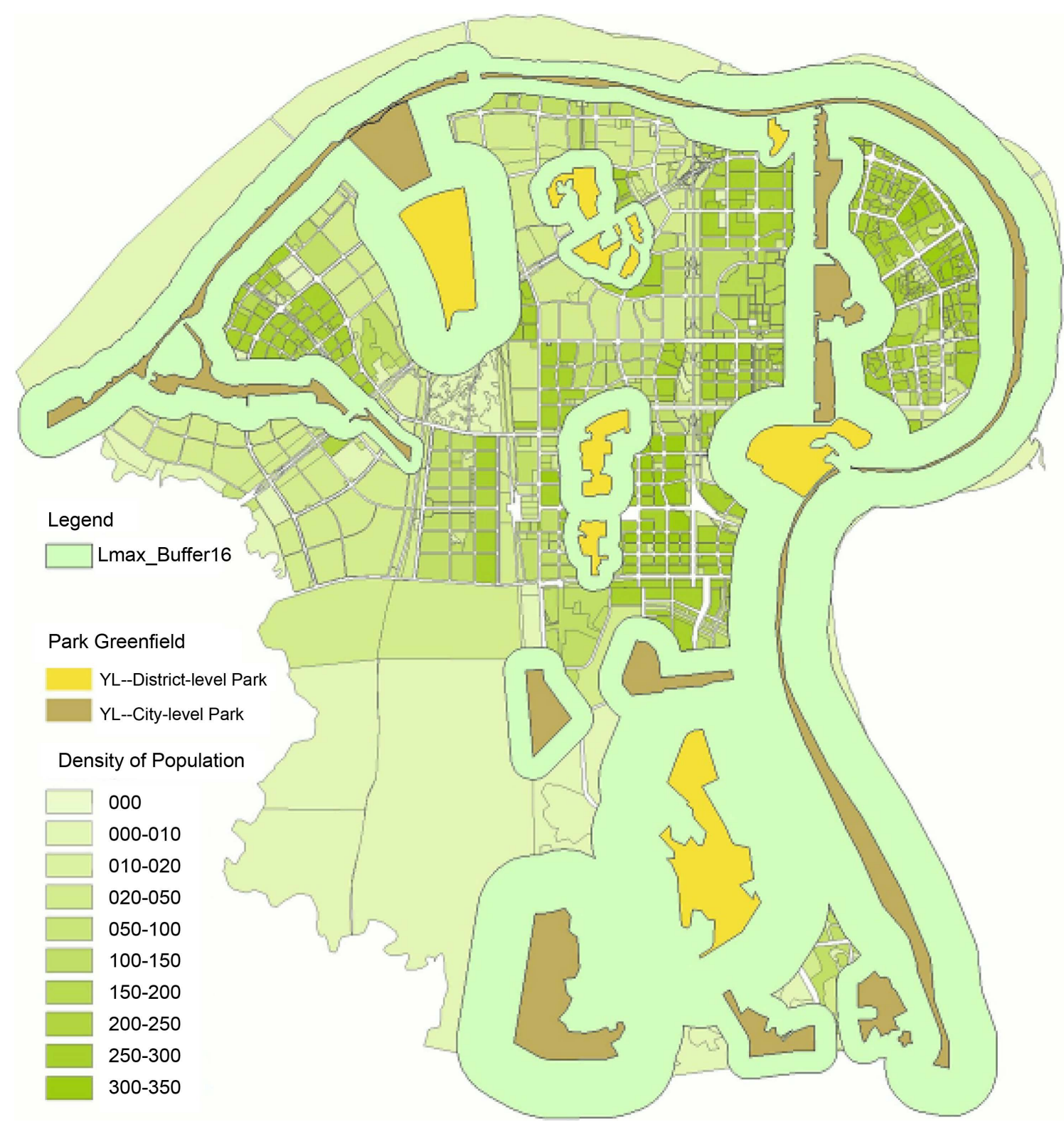

Figure 5. Overlay of the maximum range of influence and plots of land, population.

Tianyuan District is divided into five areas-Liyu, Shennong City, Xinma Industrial Park, Wuguang, Taigao Park Area and Xiangjiang New Town. As shown in Figure 9, Xiangjiang New Town has the highest service area ratio and service population ratio, and Wugang Area has a relatively low area and population affected by temperature reduction from park green spaces at less than $20 \%$. Therefore, improvement should be made to Wuguang Area. As land for agriculture and forestry, Taigao Park Area has a low population density and can be disregarded in terms of green space system planning.

\section{Discussion and Conclusion}

Divided into direct and indirect effects, the temperature reduction mechanism of urban green spaces follows a measurable law in respect to the range and degree 


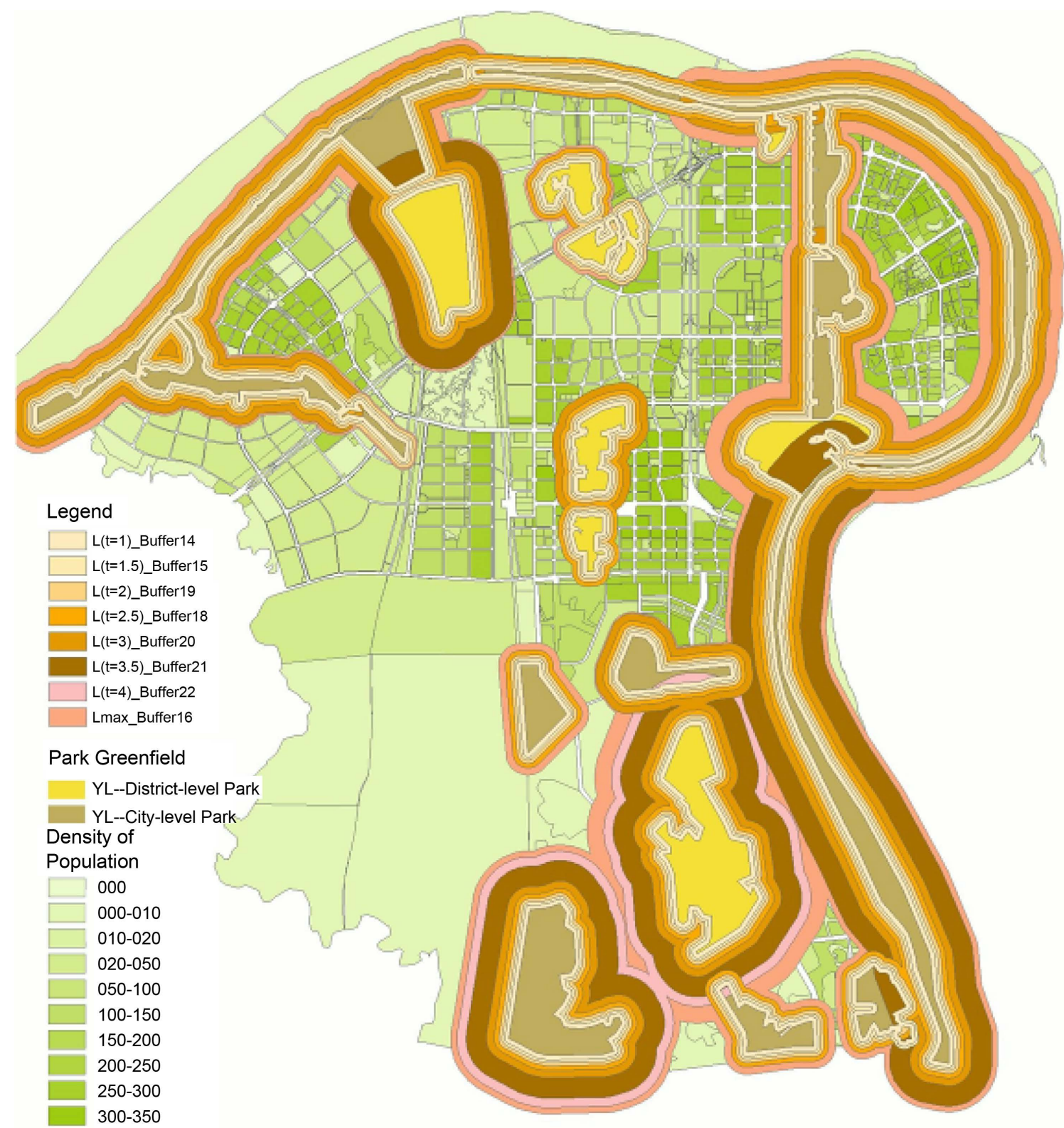

Figure 6. Overlay of the effects of different temperature range and plots of land, population.

of their impact on the surrounding thermal environment. Based on this, quantitative evaluation can be conducted $\mathrm{n}$ the thermal environment impact of urban green space system planning in combination with population and land conditions. Subsequently, the rationality of urban green space system layout can be analyzed from the perspective of ecology. As can be seen from the case study in this research, the introduction of an ecological perspective in the evaluation of urban green space system planning reveals such issues as inadequate coverage of green space impact, imbalanced regional layout and shortage of small community parks. Improvements in these aspects will create a more rational urban green space system layout.

The impact of urban green spaces on the surrounding thermal environment is not only related to the area of green spaces, but also concerned with the shape 


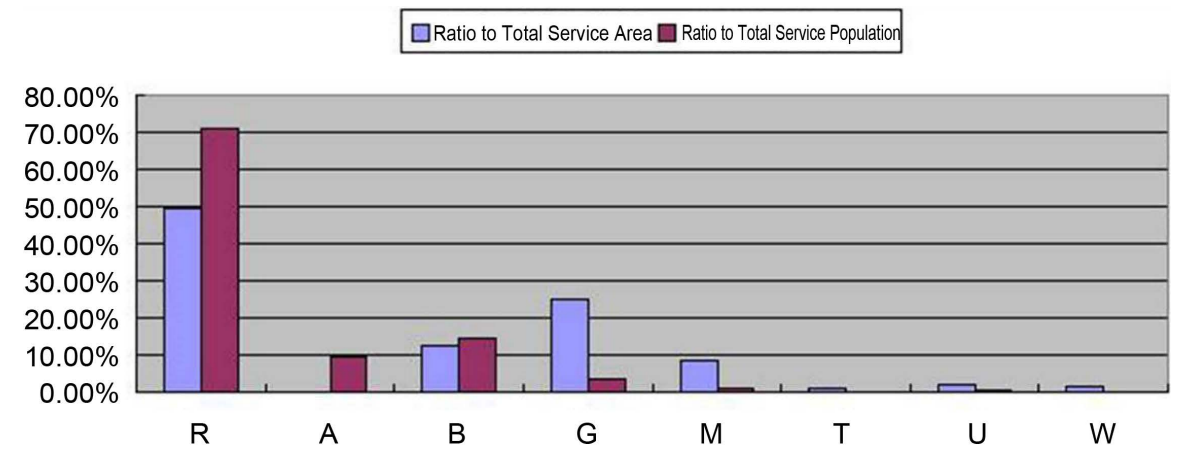

Figure 7. The affected area and population for different urban land uses.

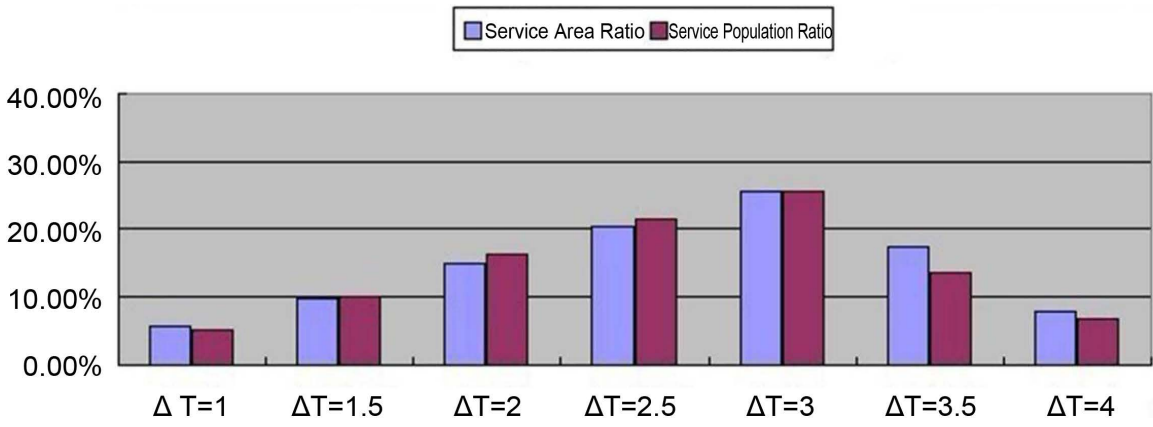

Figure 8. Statistics of temperature difference service level.

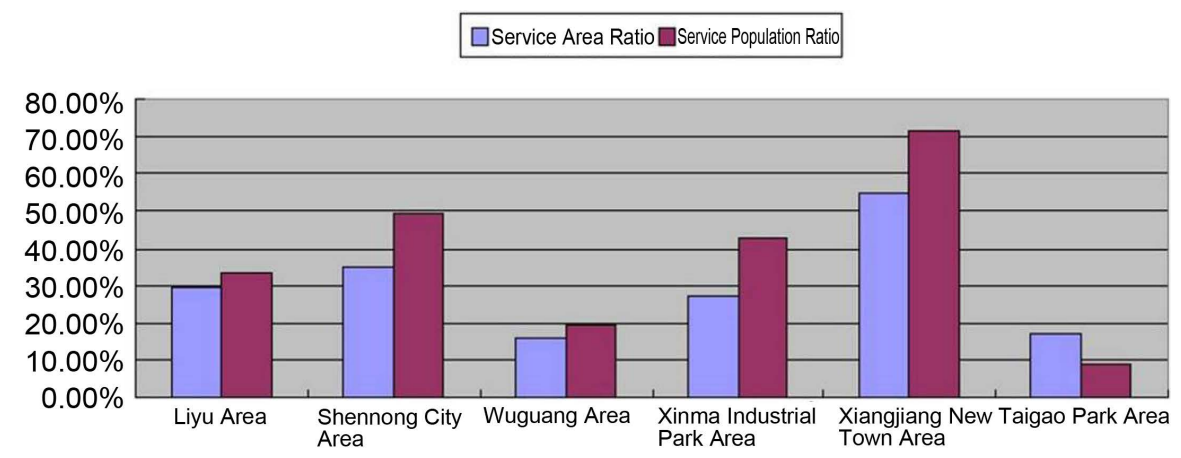

Figure 9. Statistics of service area, population of green space in different area.

and surrounding heat sources and other factors. These factors will be furthered explored in future studies. The framework of this research focusing on the thermal environment impact of green spaces can be introduced into future studies regarding carbon-oxygen balance, dust reduction and other ecological functions of green spaces for a more comprehensive ecological evaluation on urban green spaces.

The ecological evaluation of urban green space system planning is a groundbreaking work to make urban green space system planning more scientific in combination with accessibility and economic impact evaluation. From the viewpoints, contents and conclusions of this research, the following points are revealed:

1) The research findings from other disciplines should be drawn upon to expand the theoretical basis for urban green space system planning from the in- 
ter-disciplinary perspective, thus effectively improving the quality of the findings. Abundant results have been achieved in studies on the ecological effect of urban greening regarding agriculture, forestry, weather, environmental protection and measurement, which are yet to be put into practical application. As urban planning is a practical science, efforts should be made to connect, introduce and apply relevant findings.

2) In urban green space system planning, the ecological evaluation of green spaces is a weak link. To resolve the positioning issues in relation to green space system planning, more quantitative analysis and more specific conclusions are needed for guidance, so as to avoid work patterns dictated by experience and subjectivity. Only in this way can the scientific level of green space system planning be truly improved.

3) Green spaces and other urban attributes should be combined in the quantitative analysis of urban green space system planning. As for the ecological evaluation of green spaces, it's improper to analyze temperature reduction, oxygen increase and carbon decrease of green spaces from the simplex perspective of greening. Urban population, land use layout and other key attributes must be taken into consideration to analyze their interaction and generate practically significant findings. Current researchers tend to neglect such a combination which should be regarded as extremely important.

4) The quantitative evaluation of urban green space system planning can be used in the process of planning and in post-planning evaluation. In the process of planning, quantitative evaluation can effectively guide plan preparation and enhance the quality of front-end planning results; in post-planning evaluation, quantitative evaluation can provide a basis for the review and revision of planning results.

\section{References}

Fu, X. Y., Song, F., \& Ding, G. X. (2006). Discussion on Ecological Layout of City Green Space Systems. Journal of Shandong Forestry Science and Technology, No. 1.

Gao, K., Qin, J., Song, K. et al. (2009). Reduced Temperature Effects at Green Spaces of Urban Residential Areas and Analysis of Their Influence Factors. Journal of Plant Resources and Environment, 18, 50-55.

Gao, W. (2015). A Progress Research on the Urban Green Space Evaluation Index System. Resource Economization \& Environmental Protection, No. 8, 111-112.

Hao, L. Z. (2004). Study on Urban Green Open Space. Nanjing: Nanjing Forestry University.

Hu, Y. (2007). Research on Wuhan Green Space System Planning based on the Landscape Ecological Security Patterns. Wuhan: Huazhong University of Science and Technology.

Kang, B., Wang, D. X., Liu, J. J. et al. (2005). The Effects of Reducing Temperature and Increasing Humidity with Different Green Spaces in Urban Areas. Journal of Northwest Forestry University, 20, 54-56.

Lei, J. L., Liu, T., Wu, Y. Y. et al. (2011). Effects of Structural Characteristics of Urban Green Land on the Temperature-reduction in Shenzhen City. Journal of Northwest Forestry University, 26, 218-223. 
Rosenfeld, A. H., Akbari, H., Romm., J. J. et al. (1998). Cool Communities: Strategies for Heat Island Mitigation and Smog Reduction. Energy and Buildings, 28, 51-62.

Su, Y. X., Huang, G. Q., Chen, X. Z. et al. (2010). The Cooling Effect of Guangzhou City Parks on the Surrounding Environments. Acta Ecologica Sinica, 30, 4905-4918.

Sun, T. G., Xiao, R. B., Cai, Y. N. et al. (2016). Research Progress and Development Trend of Quantitative Assessment Techniques for Urban Thermal Environment. Chinese Journal of Applied Ecology, 27, 2717-2718.

Wang, X. J. (2009). Analysis of Problems in Urban Green Space System Planning in China. Journal of Forestry Research, 20, 79-82.

Wang, Y. J. (2007). The Planning Theory Study on Ecology Garden City. Nanjing: Nanjing Forestry University.

Wu, F., Li, S. H., \& Liu, J. M. (2007). Research on the Relationship between Urban Green Spaces of Different Areas and the Temperature and Humidity Benefit. Chinese Landscape Architecture, No. 6.

Wu, H. (2010). Study on Alleviation Effect of Green Spaces on the Urban Heat Island Based on GIS Hefei. Hefei: Agricultural University of Anhui.

Zhu, X. Q. (2011). Research on Evaluation of Urban Green Space System Planning Scheme Abstract. Tai'an: Shandong Agricultural University.

Submit or recommend next manuscript to SCIRP and we will provide best service for you:

Accepting pre-submission inquiries through Email, Facebook, LinkedIn, Twitter, etc. A wide selection of journals (inclusive of 9 subjects, more than 200 journals)

Providing 24-hour high-quality service

User-friendly online submission system

Fair and swift peer-review system

Efficient typesetting and proofreading procedure

Display of the result of downloads and visits, as well as the number of cited articles

Maximum dissemination of your research work

Submit your manuscript at: http://papersubmission.scirp.org/

Or contact cus@scirp.org 